\title{
Synthesis, Characterization and Biomedical Applications of p(HEMA-co-APTMACI) Hydrogels Crosslinked with Modified Silica Nanoparticles
}

\author{
Betul Yilmaz ${ }^{1}$, Ozgur Ozay ${ }^{2,3, *(D)}$ \\ 1 Department of Bioengineering and Materials Engineering, School of Graduate Studies, Çanakkale Onsekiz Mart \\ University, Çanakkale, Turkey; ybetul20@gmail.com (B.Y.); \\ 2 Department of Bioengineering, Faculty of Engineering, Çanakkale Onsekiz Mart University, Çanakkale, Turkey; \\ ozgurozay@comu.edu.tr (O.O.); \\ 3 Laboratory of Inorganic Materials, Department of Chemistry, Faculty of Science and Arts, Çanakkale Onsekiz Mart \\ University, Çanakkale, Turkey \\ * Correspondence: ozgurozay@ comu.edu.tr (O.O.);
}

Scopus Author ID 23973597600

Received: 25.05.2021; Revised: 30.06.2021; Accepted: 3.07.2021; Published: 13.08.2021

\begin{abstract}
In this study, a new silica-based crosslinker was successfully synthesized with the reaction between silica nanoparticles modified with amino groups and glycidyl methacrylate (GMA). Using the synthesized silica-based crosslinker, $\mathrm{p}$ (HEMA) and p(HEMA-co-APTMACI) hydrogels were synthesized for use as drug carrier systems with the free radical polymerization method. The synthesized silica-based crosslinker and hydrogels were characterized using scanning electron microscopy (SEM) and Fourier transform-infrared spectroscopy (FTIR) devices. The swelling behavior of hydrogels crosslinked with silica was investigated in different physiological media. The hydrogels were loaded with sodium diclofenac $(\mathrm{NaDc})$ as a model drug. Drug release studies from the obtained drug-loaded hydrogels were performed at $37^{\circ} \mathrm{C}$ in PBS (pH 7.0) media. Additionally, the antibacterial properties of the hydrogels synthesized in the study were investigated against E. coli (gram-negative), B. subtilis, and S. aureus (gram-positive) bacteria using the disk diffusion method. At the end of the study, p(HEMAco-APTMACI) hydrogels were determined to display a better drug release profile than p(HEMA) hydrogels.
\end{abstract}

Keywords: (3-acrylamidopropyl) trimethylammonium chloride; 2-hydroxyethyl methacrylate; silicabased crosslinker; drug release; hydrogel.

(C) 2021 by the authors. This article is an open-access article distributed under the terms and conditions of the Creative Commons Attribution (CC BY) license (https://creativecommons.org/licenses/by/4.0/).

\section{Introduction}

Medications administered by traditional routes like oral or subdermal injection do not provide full drug concentration equilibrium within the plasma. This situation causes a reduction in the efficacy of these drugs [1]. Additionally, high drug concentrations consumed by the oral route may lead to the emergence of various problems like cytotoxic effects and drug side effects. Studies about controlled drug release systems continue in the literature to minimize or resolve these problems involved in medications administered with traditional routes [2]. With controlled drug release systems that can direct the drugs to the target, the dosage amount of the drugs can be adjusted. Additionally, they may reduce toxic effects and ensure continuous and targeted release [3]. In recent years, various hydrogels [4], liposomes, nanoparticles, and dendrimers have been developed as drug carrier materials in the literature [5]. 
Hydrogels are cross-linked three-dimensional hydrophilic polymer networks. They can trap thousands of times their weight of fluid within their structure [6]. The crosslinker binding the linear polymeric chains within the hydrogel structure may be chemical or physical (ionic interactions, hydrogen bonds, or hydrophobic interactions [7]. Due to these cross-links, the polymeric structure can swell in fluid without dissolving [8]. Additionally, hydrogels are flexible, biodegradable, biocompatible, and have a similar soft structure to biological tissue, making them conveniently appropriate for use in internal applications [9]. Hydrogels are used in biomedical areas like tissue engineering, biosensor applications, implants, regenerative medicine, and drug release systems [10]. Hydrogels, offering many possibilities for use in the biomedical field, can be classified in many ways according to crosslinker type, environmental sensitivity, synthesis sources, and electrical charge. Hydrogels may be anionic, cationic, or neutral charge electrically according to the functional groups they contain [11]. Anionic monomers include 2-acrylamido-2-methyl-1-propanesulfonic acid, acrylic acid, itaconic acid, maleic acid, methacrylic acid, and vinyl phosphonic acid [12]. Additionally, the chain backbone of cationic monomers used for hydrogel production contains a positive charge. Examples of cationic monomers include 4-vinylpyridine (4-VP), [2-(Methacryloyloxy)ethyl] trimethylammonium chloride, 3-acrylamidopropyl) trimethylammonium chloride (APTMACl), and 2-(dimethylaminoethyl) methacrylate (DMAEMA) [13]. APTMACI is an ammonium chloride salt-containing positive charge in the structure. Due to the positive charge may form complexes with anionic biomolecules, nucleic acids, and proteins [14]. It is used as a drug carrier or in gene therapies [15]. It displays antibacterial features due to the positive charge [16]. 2-Hydroxyethyl methacrylate (HEMA) contains an - $\mathrm{OH}$ group in the structure and is non-toxic, biocompatible, and hydrophilic with similar physicochemical features to living tissues [17]. Due to these features, it is commonly used for contact lenses, drug release, artificial leather production [18], and as the skeleton for tissue engineering [19].

Hydrogels are synthesized using a variety of crosslinkers. These crosslinkers generally contain more than one vinyl group. Due to the vinyl groups in the structure, they bind linear polymeric chains together, ensuring the creation of a network structure. In the literature, generally N,N'-metylenbisacrylamide (MBA) [20], ethylene glycol dimethacrylate (EGDMA) [21], divinylbenzene [22], di(ethylene glycol) dimethacrylate (DEGDMA), bis(2methacryloyl)oxyethyl disulfide [23], and tripropyleneglycol diacrylate [24] are used as crosslinkers.

Silica nanoparticles can be easily modified to gain the desired features due to their surface's silanol ( $\mathrm{Si}-\mathrm{OH})$ groups. Due to these features, silica nanoparticles are frequently used as catalyst support material, sensors, and controlled drug release systems in the literature. In this study, silica nanoparticles which can be easily synthesized in monodispersed form and modified in a single step were designed as crosslinkers. Thus, biocompatible silica nanoparticles, easily synthesized and low toxicity, were used as crosslinkers [25]. With this aim, silica nanoparticles containing $-\mathrm{NH}_{2}$ groups on their surface were reacted with glycidyl methacrylate to synthesize inorganic/organic hybrid crosslinker nanoparticles containing many vinyl groups on the surface. Then the obtained vinyl functional silica nanoparticles were structurally characterized. This new type of silica-derived crosslinker was used to cross-link APTMACI and HEMA. The hydrogels obtained were characterized by scanning electron microscopy (SEM), Fourier transform infrared spectroscopy (FTIR), and investigating swelling features. The synthesized and characterized hydrogels were used to release sodium diclofenac $(\mathrm{NaDc})$ drug at $37^{\circ} \mathrm{C}$ in phosphate buffer solution (PBS). Finally, the antibacterial 
activities of the hydrogels synthesized with this new type of crosslinker were investigated against Staphylococcus aureus, Bacillus subtilis, and Escherichia coli.

\section{Materials and Methods}

\subsection{Materials.}

Tetraethyl orthosilicate (TEOS) used as a monomer for silica nanoparticle synthesis was purchased from Sigma-Aldrich, and APTMACI (75\% wt.\% in $\mathrm{H}_{2} \mathrm{O}$ ) and HEMA (97\%) used as monomers for hydrogel synthesis were obtained from Sigma-Aldrich and Acros Organics, respectively. The (3-Aminopropyl)triethoxysilane (APTES) and glycidyl methacrylate (GMA) (97\%) used for modification processes for silica nanoparticles, ammonium persulfate (APS) used as initiator for polymerization, $N, N, N^{\prime}, N^{\prime}-$ tetramethylethylenediamine (TEMED) (Sigma Aldrich) used as accelerator, and sodium diclofenac used as a model drug were purchased from Acros Organics. Dimethyl sulfoxide (DMSO), toluene, ethanol, and ammonium hydroxide solution were obtained from Sigma Aldrich; dichloromethane, tryptic soy broth (TSB), and tryptic soy agar (TSA) were obtained from Merck. All solvents and chemicals used in experiments were used without purification. Additionally, distilled water was used for all hydrogel synthesis, swelling, and drug release studies.

\subsection{Synthesis and Modification of silica nanoparticles.}

Nanoparticle synthesis was carried out with the Stöber method [26]. For this, within a reaction flask at room temperature, $30 \mathrm{~mL}$ distilled water, $4 \mathrm{~mL}$ ammonium hydroxide, and 50 $\mathrm{mL}$ ethyl alcohol were added in order and mixed at $1000 \mathrm{rpm}$. Then, $1 \mathrm{~mL}$ TEOS dissolved in $25 \mathrm{~mL}$ ethyl alcohol was added to the reaction flask, and the reaction began. The reaction was continued for 24 hours under the same conditions. The mixture obtained at the end of the reaction duration was centrifuged at $6000 \mathrm{rpm}$. The product obtained was washed a few times in distilled water and then ethyl alcohol. Then it was dried in an oven at $110^{\circ} \mathrm{C}$ for $6 \mathrm{~h}$.

To modify the synthesized silica nanoparticles, $0.2 \mathrm{~g}$ pure silica nanoparticles were added to $5 \mathrm{~mL}$ toluene. Then, $0.25 \mathrm{~mL}$ 3-(triethoxysilyl-propylamine (APTES) was added to the reaction medium. The reaction mixture was refluxed for 2 days, stirring at $700 \mathrm{rpm}$ under an argon atmosphere [27]. At the end of the duration, the modified nanoparticles in the mixture were precipitated with a centrifuge $(6000 \mathrm{rpm}, 25 \mathrm{~min})$. The nanoparticles washed with $2 \times 50$ $\mathrm{mL}$ dichloromethane and precipitated (amine-SiNP) were dried and stored for characterization and crosslinker synthesis.

\subsection{Synthesis of SiNP-based crosslinker.}

Crosslinker silica nanoparticles were synthesized due to the reaction of silica nanoparticles (amine-SiNP) whose surfaces contain amine groups with GMA in DMSO. For this purpose, $100 \mathrm{mg}$ amine-SiNP were suspended within DMSO $(10 \mathrm{~mL})$. Then, $1.5 \mathrm{~mL}$ GMA was added to the reaction medium. The reaction was continued at room temperature with a 750 rpm mixing rate for $24 \mathrm{~h}$. At the end of this duration, the reaction mixture was precipitated with the aid of a centrifuge (6000 rpm, $25 \mathrm{~min}$ ) and washed with $2 \times 10 \mathrm{~mL}$ DMSO firstly and then with $10 \mathrm{~mL}$ ethanol to remove impurities. After washing, the synthesized crosslinker nanoparticles were dried in a vacuum oven at $45^{\circ} \mathrm{C}$. 


\subsection{Synthesis of $p(H E M A)$ and $p$ (HEMA-co-APTMACI) cross-linked with silica} nanoparticles.

The redox polymerization method synthesized hydrogels cross-linked with silica nanoparticles containing vinyl groups on their surface. To synthesize p(HEMA) hydrogels, 2 mg silica nanoparticles as crosslinkers were suspended within 16.45 mmol HEMA. Then, TEMED $(40 \mu \mathrm{L})$ as an accelerator was added to the mixture. APS as initiator at 1-mole percent of monomer was dissolved in $100 \mu \mathrm{L}$ distilled water in a separate vial. The APS solution was added to the reaction mixture, and the polymerization reaction began. With the aim of giving the mixture a cylindrical shape, the reaction mixture was rapidly transferred into a straw with an injector. The mixture was left at room temperature for $2 \mathrm{~h}$ to complete the reaction. Additionally, the synthesis of p(HEMA-co-APTMACI) copolymeric hydrogels was carried out with a monomer mole ratio of 1:1. For synthesis, $20 \mathrm{mg}$ silica nanoparticles as crosslinkers were added to a vial. Then 16.45 mmol HEMA and $16.45 \mathrm{mmol}$ APTMACI were added to the crosslinker and mixed until homogeneous distribution was obtained. Then $100 \mu \mathrm{L}$ TEMED was added to the reaction mixture. Finally, APS (in $100 \mu \mathrm{L}$ distilled water) was added to the reaction mixture as molar $1 \%$ of total monomers, and the reaction began. After $2 \mathrm{~h}$, all hydrogels were washed in distilled water for one day $(5 \times 100 \mathrm{~mL})$ to remove unreacted reactive from the hydrogel network structure. At the end of washing, the cleaned hydrogels were cut to sizes of about $0.5 \mathrm{~cm}$ and dried in a vacuum oven at $45^{\circ} \mathrm{C}$.

\subsection{Swelling characterization of $p($ HEMA) and p(HEMA-co-APTMACI) hydrogels.}

It is important that hydrogels to be used for biomedical purposes can swell in various fluid media. With this aim, swelling studies for hydrogels were performed in distilled water, phosphate buffer solution, and simulated stomach fluid. Within $500 \mathrm{~mL}$ distilled water, phosphate buffer solution (PBS, pH 7.0) was prepared using $2.5 \mathrm{~g} \mathrm{KH}_{2} \mathrm{PO}_{4} \mathrm{H}_{2} \mathrm{O}$ and $4.29 \mathrm{~g}$ $\mathrm{Na}_{2} \mathrm{HPO}_{4} .2 \mathrm{H}_{2} \mathrm{O}$ and simulated gastric fluid (SGF, $\mathrm{pH} 1.2$ ) was prepared using $1.0 \mathrm{~g} \mathrm{NaCl}$ and $2 \mathrm{~mL} \mathrm{HCl}(37 \%)$. Solutions of $0.1 \mathrm{M} \mathrm{HCl}$ and $\mathrm{NaOH}$ were used to set the $\mathrm{pH}$ of the solutions. To prepared solutions, were added hydrogels with known dry weight, and the mass increase at specific times was plotted as a function of time. The swelling amounts for hydrogels in distilled water, PBS, and SBF were calculated using the following equation (Eq. 1) [28].

$S=\frac{m_{t}-m_{0}}{m_{t}}$

Here, $\mathrm{S}$ is the swelling ratio of hydrogels $\left(\mathrm{g}_{\text {water }} / \mathrm{g}_{\mathrm{gel}}\right)$; and $\mathrm{m}_{\mathrm{t}}$ and $\mathrm{m}_{0}$ are the gel mass (g) at time $t$ and initial dry mass of gel $(\mathrm{g})$.

To determine the swelling profiles of hydrogels, a variety of mathematical models are used. One of the most commonly used kinetic models is the pseudo-second-order kinetic model which is determined according to Eq. 2.

$\frac{t}{S}=A+B t$

Here, A $\left(1 / \mathrm{S}_{\max }{ }^{2} \cdot \mathrm{k}_{\mathrm{s}}\right)$ is the initial swelling rate for the hydrogel; and $\mathrm{B}\left(1 / \mathrm{S}_{\max }\right)$ represents the inverse of the maximum swelling rate achieved by the hydrogel [29]. 
The diffusion exponential $(\mathrm{n})$ and the diffusion rate constant $(\mathrm{k})$ determining the diffusion mechanism for swelling kinetics are other important parameters. These values are determined according to Eq. 3 and Eq. 4.

$F=\frac{M_{t}}{M_{\infty}}=k t^{n}$

(Eq. 3)

$D^{n}=k \frac{\left(\pi r^{2}\right)^{n}}{4}$

In Eq. 3, known as Fick's diffusion law, $\mathrm{M}_{\mathrm{t}}$ is the amount ( $\mathrm{g}$ ) of water adsorbed by the hydrogels at time $\mathrm{t} ; \mathrm{M}_{\infty}$ is the amount $(\mathrm{g})$ of water adsorbed by the hydrogel at equilibrium, and $\mathrm{F}$ is the swelling fraction. If the ' $\mathrm{n}$ ' value included in Fick's law is less than 0.45 , the mechanism is less-Fickian diffusion. If $n=0.45$, the mechanism is Fickian, while if $0.45<\mathrm{n}<0.89$, the mechanism is non-Fickian. If the $\mathrm{n}$ value is equal to 0.89 , it is Case II diffusion, while if it is larger than 0.89, it is supercase-II diffusion [30][31]. In Eq. 4, D is the diffusion coefficient, and $\mathrm{r}$ is the radius of the hydrogel $(\mathrm{cm})$ [29].

\subsection{Drug loading and release of p(HEMA) and p(HEMA-co-APTMACI) hydrogels.}

For drug release studies from hydrogels, $200 \mathrm{mg} / \mathrm{L}(50 \mathrm{~mL})$ concentration NaDc drug prepared in distilled water was used. For drug loading into hydrogels, nearly 0.1-0.3 g of hydrogel was added to the drug solution. The hydrogels were left for nearly $48 \mathrm{~h}$ in the drug solution for drug adsorption. At the end of this duration, the amount of drug absorbed by the hydrogel was determined using a UV-Vis spectrophotometer. In vitro drug release studies of the drug-loaded hydrogels were performed in PBS ( $\mathrm{pH}$ 7.0) medium. At certain time intervals, $3 \mathrm{~mL}$ of solution was taken from the release medium, and the amount of drug released was determined from the absorbance value at $\lambda \max =276 \mathrm{~nm}$ using a $\mathrm{UV}$-Vis spectrophotometer. To calculate drug adsorption and drug release amounts, Eq. 5 and Eq. 6 were used [32].

$q_{t}=\frac{\left(C_{0}-C_{e q}\right) V}{m}$

$q_{t}=\frac{\left(C_{t}\right) V}{m}$

Here, $\mathrm{C}_{0}$ is the initial drug concentration; $\mathrm{C}_{\mathrm{eq}}$ is the equilibrium drug concentration remaining in the drug solution; $\mathrm{V}$ is the volume $(\mathrm{L})$ of the solution; $\mathrm{m}$ is the dry mass $(\mathrm{g})$ of the hydrogel, and $\mathrm{C}_{\mathrm{t}}$ is the drug concentration released by the hydrogel at time $\mathrm{t}$.

To investigate the release parameters for drugs released from hydrogels, Eq. 7 (Korsmeyer-Peppas power-law) was used [33].

$\frac{\log C_{t}}{C_{\infty}}=\log K+n \log t$

In Eq. $7, \mathrm{C}_{\mathrm{t}}$ is the drug concentration released at time $\mathrm{t}$; $\mathrm{C}_{\infty}$ is the drug concentration at equilibrium; $\mathrm{K}$ is the drug release rate constant, and $\mathrm{n}$ is the drug release exponential linked to time $\mathrm{t}$. 


\subsection{Antibacterial activity.}

Hydrogels with positive load due to monomers in the structure are expected to have antibacterial activity. With this aim, the antibacterial properties of the hydrogels were investigated using the disk diffusion method. The gram-negative bacteria E. coli and grampositive bacteria $B$. subtilis and $S$. aureus were used for antibacterial tests. Bacteria were cultured on broth agar at $37{ }^{\circ} \mathrm{C}$. From bacterial suspensions, $30 \mu \mathrm{L}$ was taken and spread on agar plates. All samples were sterilized with UV light before use. Then hydrogels (unloaded and drug-loaded hydrogels) were placed on the Petri dishes and incubated overnight at $37{ }^{\circ} \mathrm{C}$. At the end of this time, inhibition diameters were measured.

\section{Results and Discussion}

\subsection{Synthesis and characterization.}

Researchers in the biomedical field frequently use silica nanoparticles due to being biocompatible, easily synthesized, having low cytotoxicity, broad surface area, and high modification possibilities [34]. Due to the silanol groups in the structure, they may easily gain $-\mathrm{NH}_{2}$ functions. These amine groups in the structure of silica nanoparticles make them suitable for reactions with GMA. Thus, a crosslinker was obtained containing many vinyl groups on the exterior surface with silica nanoparticles in the core. In this way, an alternative crosslinker for the synthesis of hydrogel structures was obtained, which generally use organic molecules. Within the scope of the study, all these features of silica nanoparticles were used, and a new type of silica-based crosslinker was synthesized. This synthesized crosslinker was used for the production of hydrogels with a network structure and antimicrobial features.

The synthesis of the silica-based crosslinker has occurred in 3 steps. The synthesis schema is given in Figure 1(a). Accordingly, in the first step, silica nanoparticles were synthesized with the Stöber method. The Stöber method is a sol-gel reaction involving hydrolysis and condensation steps. The synthesized silica nanoparticles contained countless amounts of $-\mathrm{OH}$ groups on the surface. These $-\mathrm{OH}$ groups allow easy modification of the nanoparticles [35]. In the second step, using the $-\mathrm{OH}$ groups on the surface of the silica nanoparticles, they were modified with APTES, and silica nanoparticles containing amine groups on the surface were obtained. The final step was the synthesis of a crosslinker containing vinyl groups. The GMA molecules have an epoxy ring at the tip and contain vinyl groups. During the reaction, the epoxy ring opens and binds with a covalent bond to amine groups found on the surface of the silica nanoparticles [36]. Thus, silica nanoparticles containing countless vinyl groups on the surface were obtained as a silica-based crosslinker. Due to these vinyl groups on the silica surface, they may be used as inorganic/organic hybrid crosslinkers for hydrogel synthesis. The synthesized crosslinker was used to synthesize biocompatible hydrogels of p(HEMA) with no load on the surface and p(HEMA-co-APTMACI) with cationic features with $96.8 \%$ and $94.9 \%$ yield, respectively (Figure 2(a)). 
(a)
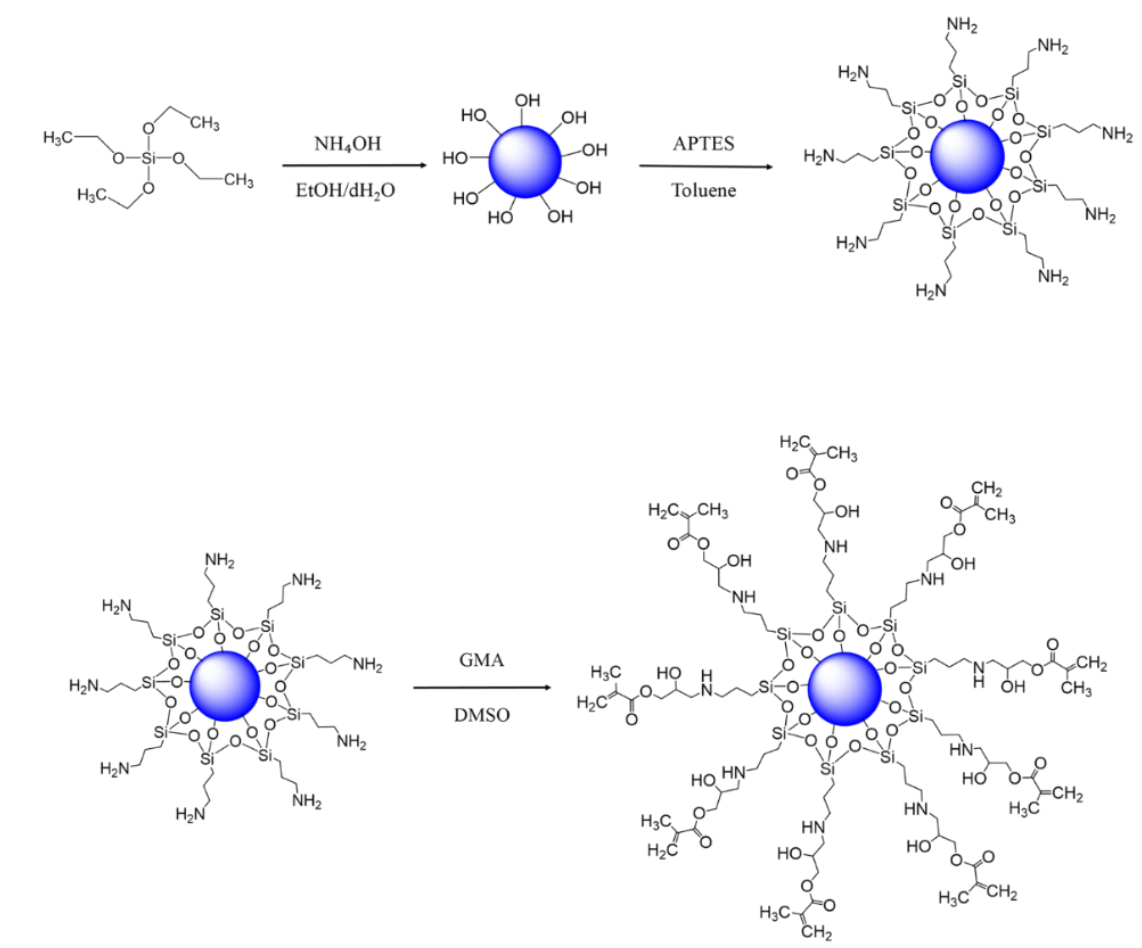

(b)

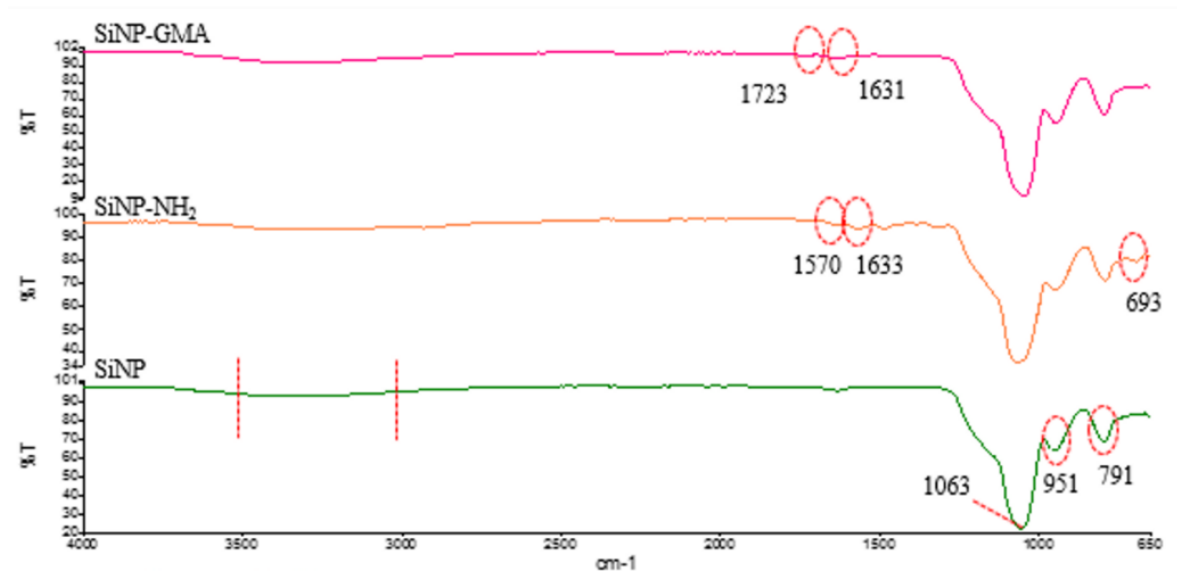

Figure 1. (a) Schematic representation of the synthesis of crosslinker silica nanoparticles; (b) FT-IR spectra of crosslinker silica nanoparticles.

As the first step of characterization for the nanoparticles, the FTIR spectra of silica nanoparticles and crosslinker were recorded and given in Figure 1(b). According to the spectrum, the characteristic peaks at $1063 \mathrm{~cm}^{-1}$ and $791 \mathrm{~cm}^{-1}$ are related to the asymmetric and symmetric stretching of $\mathrm{Si}-\mathrm{O}-\mathrm{Si}$ bonds. The peak at $951 \mathrm{~cm}^{-1}$ is asymmetric stretching of the $\mathrm{Si}-\mathrm{O}$ bond [37]. The $-\mathrm{OH}$ stretching vibrations were observed as the broadband in the 3000$3500 \mathrm{~cm}^{-1}$ [38]. Additionally, the peaks at $1570 \mathrm{~cm}^{-1}, 693 \mathrm{~cm}^{-1}$, and $1633 \mathrm{~cm}^{-1}$ are related to N$\mathrm{H}$ bending vibrations of amine-SiNP [39]. However, $\mathrm{N}-\mathrm{H}$ stretching vibrations were observed as overlapped with $\mathrm{OH}$ - stretching vibrations in the interval $3000-3500 \mathrm{~cm}^{-1}$. The peaks at 1720 $\mathrm{cm}^{-1}$ and $1631 \mathrm{~cm}^{-1}$ in the spectrum are related to $\mathrm{C}=\mathrm{O}$ carbonyl group stretching $\mathrm{C}=\mathrm{C}$ stretching, respectively [40]. These results show the crosslinker was synthesized successfully. Additionally, $\mathrm{N}-\mathrm{H}$ and $-\mathrm{OH}$ stretching vibrations of crosslinker silica nanoparticles were observed as overlapped in the interval $3000-3500 \mathrm{~cm}^{-1}$ after GMA modification. 
(a)

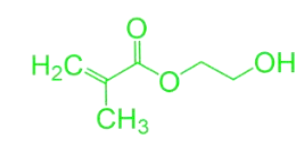

HEMA
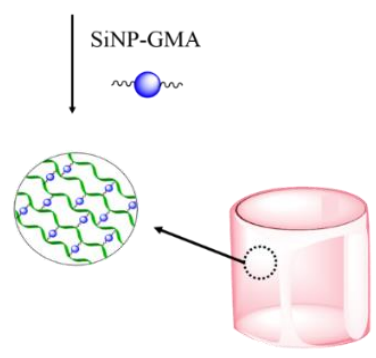

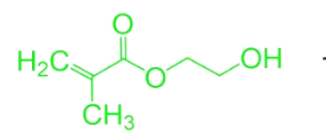

HEMA

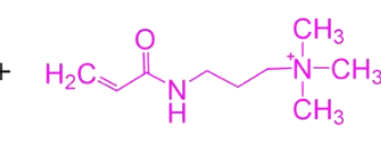

APTAMCl

(b)

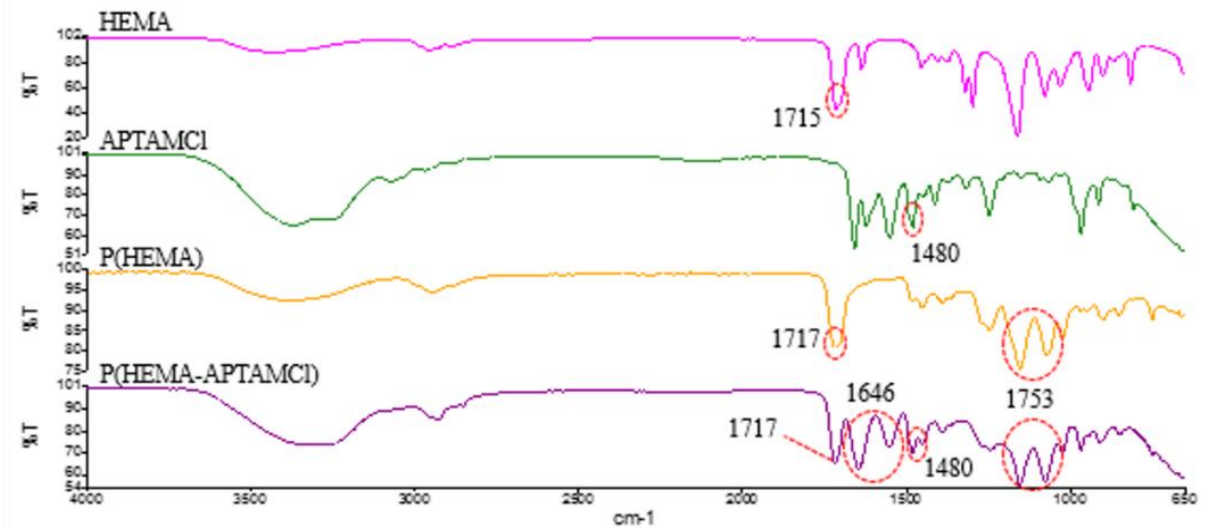

Figure 2. (a) Schematic representation of cross-linked hydrogels; (b) FT-IR spectra of p(HEMA) and p(HEMAco-APTMACl) hydrogels.

The FTIR spectra for hydrogels synthesized using the silica-based crosslinker created by modification of silica spheres are given in Figure 2(b). Firstly, hydrogels were successfully cross-linked and did not dissolve in aqueous media after synthesis, proving that both crosslinker silica nanoparticles were successfully synthesized and that the silica-based nanoparticles easily cross-linked hydrogels. Additionally, as shown in Figure 2(b), for the HEMA monomer, the characteristic peak value at $1715 \mathrm{~cm}^{-1}$ is related to $\mathrm{C}=\mathrm{O}$ ester stretching vibrations [41]. For the APTMACI monomer, the characteristic peak at $1480 \mathrm{~cm}^{-1}$ is attributed to $\mathrm{N}-\mathrm{H}$ bending in the ammonium group [42]. Additionally, the sharp peak value obtained at $1717 \mathrm{~cm}^{-1}$ for $\mathrm{p}$ (HEMA-co-APTMACI) hydrogels is related to $\mathrm{C}=\mathrm{O}$ stretching vibration from the ester group in HEMA, while values at $1153 \mathrm{~cm}^{-1}$ and $1075 \mathrm{~cm}^{-1}$ are attributed to $\mathrm{C}-\mathrm{O}$ stretching vibrations [43]. Again, the peak values at $1552 \mathrm{~cm}^{-1}$ and $1646 \mathrm{~cm}^{-1}$ in the $\mathrm{p}(\mathrm{HEMA}-$ co-APTMACI) hydrogel spectrum are related to $\mathrm{N}-\mathrm{H}$ and $\mathrm{C}=\mathrm{O}$ stretching vibrations from secondary amide groups [44]. With the assessment of the spectra obtained as a result of FTIR analysis, it can be said that both novel crosslinkers and hydrogels were successfully synthesized. 

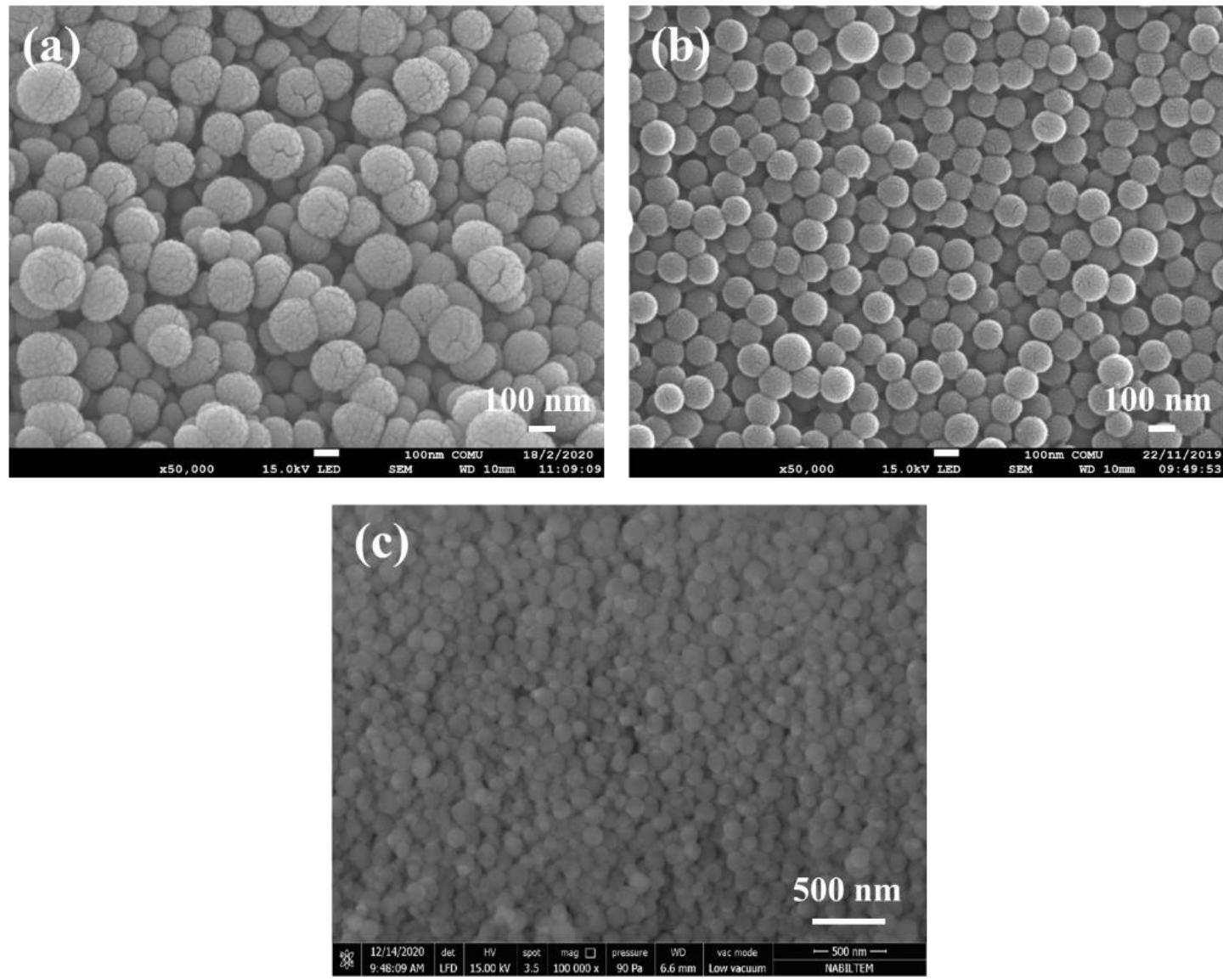

Figure 3. SEM images of silica nanoparticles (a) pure silica nanoparticles; (b) amine-modified silica nanoparticles; (c) GMA-modified silica nanoparticles (crosslinker).

SEM analysis was performed to investigate the surface morphology and pore structure of silica nanoparticles and hydrogels. The SEM images of silica nanoparticles can be seen in Figure 3. Figure 3(a) shows the silica nanoparticles synthesized with the Stöber method. As seen from the figure, the nanoparticles successfully synthesized are monodispersed and spherical form [45]. Their dimensions are nearly $100 \mathrm{~nm}$. Figure 3(b) and Figure 3(c) show the SEM images for the amine-modified and GMA-modified silica nanoparticles, respectively. After the modifications, the nanoparticles preserved their spherical and monodispersed features, and their dimensions did not change. SEM analyses of hydrogels were performed after following freeze-drying swelling in water to the maximum rates in distilled water. Thus, the pores in the hydrogels expand in water, and the pore structure of the hydrogels is preserved without disruption by drying with the freeze-drying process. The SEM images for p(HEMA) and $\mathrm{p}$ (HEMA-co-APTMACI) hydrogels are given in Figure 4. The p(HEMA) hydrogels have low amounts of very small pores in the structure (Figure 4(b)). Apart from these, there is an almost smooth surface [46]. From the SEM image of p(HEMA-co-APTMACI) hydrogels, they appear to have larger pores (Figure 4(a)). This broad porous structure is due to the electrostatic repulsion force between cationic groups in the APTMACI monomer and ions in water. Large porous structures increase the surface area of hydrogels. Increasing surface area ensures more adsorption of compounds such as drug-active materials and dye agents by the hydrogels. Cationic monomers are observed to cause more rigidity in the hydrogel network and increase the pore dimensions and amounts in the hydrogel. This situation highly increases the waterholding capacity of the hydrogel. When images of both hydrogels are examined, spherical shapes are observed in the structure. This confirms the presence of the newly synthesized silicabased crosslinker. 

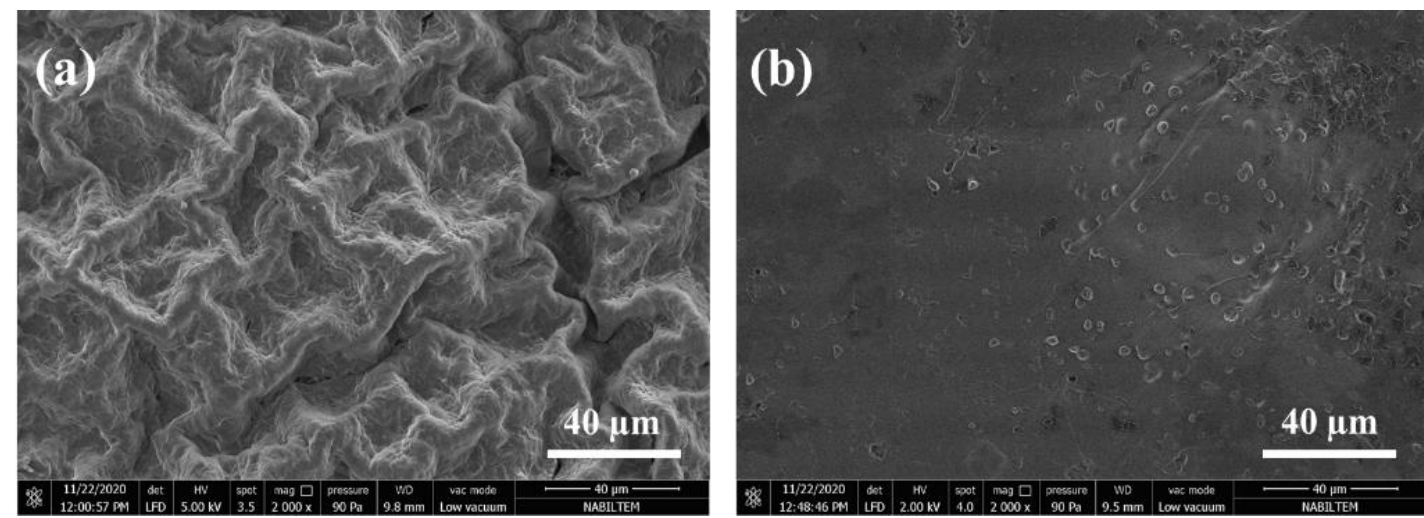

Figure 4. SEM images of hydrogels (a) p(HEMA-co-APTMACl); (b) p(HEMA).

\subsection{Swelling studies.}

Swelling studies provide important data about the characteristic structures of hydrogels. Swelling begins with the diffusion of the solvent media into the hydrogel network structure. After a certain duration, the entry rate of the solvent into the network structure and the release rate from the hydrogel equilibrate and swelling stop. This shows that hydrogels reach maximum swelling values at equilibrium [47]. Swelling rates are an important parameter for hydrogel material to be used for drug release systems to set the drug release amounts.
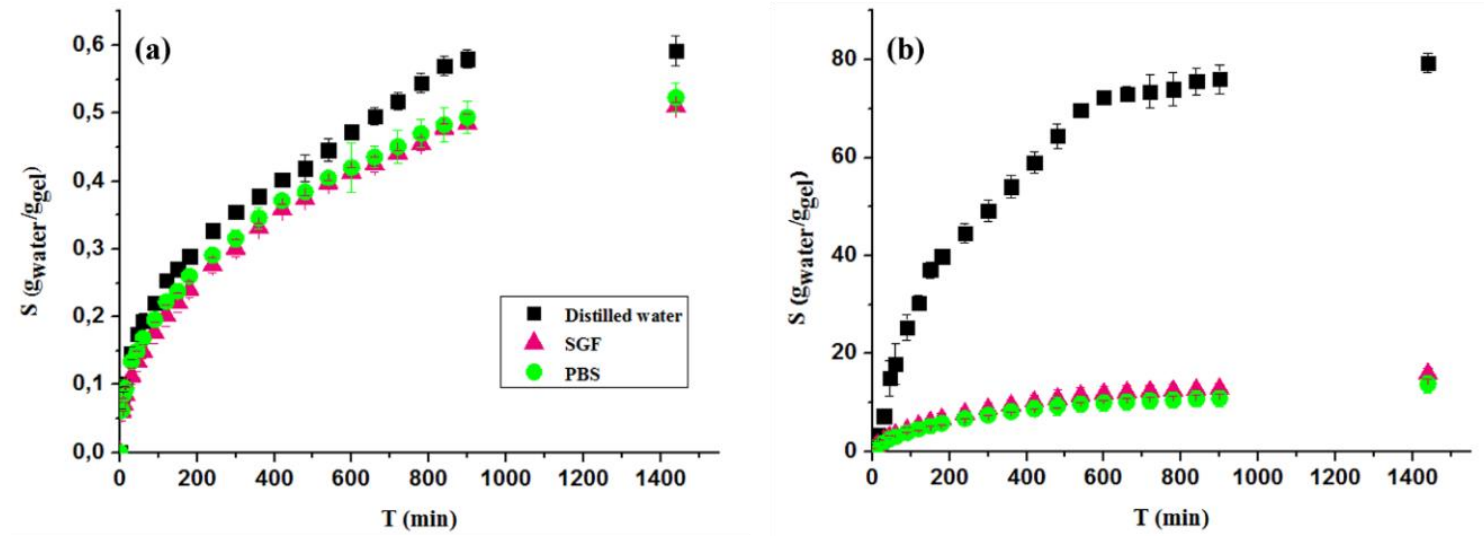

Figure 5. Swelling kinetics of (a) p(HEMA) and (b) p(HEMA-co-APTMACl) hydrogels.

Time-linked swelling experiments were performed in a variety of biological media to investigate the swelling behavior of hydrogels. The swelling profiles of hydrogels and digital camera images of hydrogels swollen in distilled water were given in Figure 5 and Figure 6 , respectively. The p(HEMA) hydrogels have a non-ionic, neutral structure. For this reason, they are not sensitive to $\mathrm{pH}$. The swelling ratio for hydrogels in distilled water, SGF, and PBS were $0.59,0.51$, and $0.52 \mathrm{~g}_{\text {water }} / \mathrm{g}_{\mathrm{gel}}$, respectively.

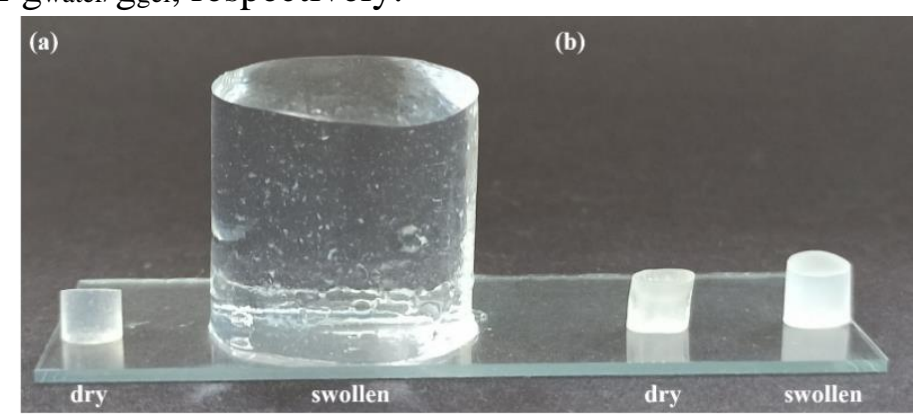

Figure 6. Digital camera images of dry and swollen hydrogels (a) p(HEMA-co-APTMACl); (b) p(HEMA). 
The swelling ratio for $\mathrm{p}$ (HEMA-co-APTMACI) hydrogels in distilled water, SGF, and PBS media were 79.30. 15.84 and $13.75 \mathrm{~g}_{\text {water }} / \mathrm{g}_{\text {gel }}$, respectively. The hydrogel was observed to adsorb more water in distilled water compared to SGF and PBS media. The reason for this is due to the increasing concentration difference between mobile ions in the hydrogel structure and the medium linked to the amount of salt present in the simulated biological media [7]. When SGF and PBS media are compared, the hydrogels appear to have more swelling capacity within SGF. The reason for this is the presence of increasing $\mathrm{H}^{+}$ions in lower $\mathrm{pH}$ media (SGF). This provides electrostatic repulsion between ammonium ions included in the APTMACI structure and the $\mathrm{H}^{+}$ions. The network structure of the hydrogel expands. Due to the expanding network structure, the water absorption capacity of the hydrogels increases [48]. The presence of APTMACI monomer with cationic features in the copolymer hydrogel appears to increase the swelling ratio of the hydrogel.

Kinetic mathematical models are used to understand and interpret the water absorption kinetics of hydrogels. Most swelling processes in hydrogels are modeled with the pseudosecond-order kinetic model.

Table 1. Diffusion parameters of the $\mathrm{p}(\mathrm{HEMA}-\mathrm{co}-\mathrm{APTMACl})$ and $\mathrm{p}(\mathrm{HEMA})$ hydrogels.

\begin{tabular}{c|c|c|c|c|c|c}
$\mathbf{p}$ (HEMA-co-APTMACI) & $\mathbf{S}_{\mathbf{m a x}}$ & $\mathbf{k s}_{\mathbf{s}}$ & $\mathbf{r}_{\mathbf{0}}$ & $\mathbf{n}$ & $\mathbf{k}$ & $\mathbf{D}$ \\
\hline Distilled water & 104,16 & $3,126 \times 10^{-5}$ & 0,339 & 1,0038 & 0,00317 & $1,038 \times 10^{-4}$ \\
\hline SGF & 14,79 & $4,086 \times 10^{-4}$ & 0,089 & 0,6138 & 0,0177 & $1,84 \times 10^{-5}$ \\
\hline PBS & 12,44 & $5,06 \times 10^{-4}$ & 0,078 & 0,6346 & 0,016 & $2,09 \times 10^{-5}$ \\
\hline p(HEMA) & & & & & & \\
\hline Distilled water & 0,597 & 0,0132 & $4,69 \times 10^{-3}$ & 0,387 & 0,0659 & $4,85 \times 10^{-6}$ \\
\hline SGF & 0,516 & 0,0143 & $3,8 \times 10^{-4}$ & 0,4098 & 0,056 & $5,87 \times 10^{-6}$ \\
\hline PBS & 0,517 & 0,0164 & $4,38 \times 10^{-4}$ & 0,3939 & 0,0642 & $5,46 \times 10^{-6}$
\end{tabular}

The swelling rate constant determining swelling rate $\mathrm{k}_{\mathrm{s}}$, initial swelling rate $\mathrm{r}_{0}$ and theoretical equilibrium swelling rate $S_{\max }$ are obtained by drawing the graph of $t / S$ against $t$. When Table 1 is examined, the initial swelling rates for the copolymeric hydrogel are much higher than the initial swelling rate for p(HEMA) hydrogel. With the calculated regression values, it was concluded that it abided by the pseudo-second-order kinetic model. The $n$ values for p(HEMA) hydrogel in distilled water, SGF, and PBS media were 0.39, 0.41, and 0.39, respectively. This abides by the Fick diffusion type. For p(HEMA-co-APTMACI) hydrogel, the diffusion exponential ' $n$ ' in SGF and PBS media were 0.61 and 0.64 . The $n$ values determining diffusion type appear to be larger than 0.45 for both media. This shows the diffusion type has a non-Fickian profile. For the distilled water medium, the $\mathrm{n}$ value is 1.00 , which shows supercase II diffusion mechanism.

\subsection{Drug loading and release studies.}

Within this scope, the usage of the $\mathrm{p}$ (HEMA) and $\mathrm{p}$ (HEMA-co-APTMACI) polymer hydrogels synthesized using silica-based crosslinker as potential drug carrier systems were investigated. The non-steroidal anti-inflammatory drug (NSAID) sodium diclofenac was used as a model drug [49]. Sodium diclofenac was loaded into hydrogels at room temperature in distilled water. The drug amounts loaded into hydrogels and released by them were analyzed using a UV-Vis spectrophotometer from the absorbance values related to sodium diclofenac at $\lambda=276 \mathrm{~nm}$. The loaded drug amount to $\mathrm{p}(\mathrm{HEMA})$ hydrogels was $2.3 \mathrm{mg}$ drug $/ \mathrm{g}_{\mathrm{gel}}$, while the loaded drug amount to $\mathrm{p}$ (HEMA-co-APTMACI) hydrogels was $34 \mathrm{mg} \mathrm{grug}_{\mathrm{g}} / \mathrm{g}_{\mathrm{gel}}$. This difference in the amount of drug-loaded hydrogels can be explained by the interactions between the drug and the hydrogel matrix. Sodium diclofenac may be adsorbed by p(HEMA) hydrogel thanks to 
hydrogen bond interactions. However, the anionic groups $\left(\mathrm{COO}^{-}\right)$in the sodium diclofenac structure have a high affinity for the quaternized ammonium groups present in p(HEMA-coAPTMACI) hydrogels, and drug molecules are loaded into this hydrogel with electrostatic interactions. For this reason, the drug-loading efficiency was much higher for cationic hydrogels compared to $\mathrm{p}$ (HEMA) hydrogels. This result shows that $\mathrm{p}$ (HEMA-co-APTMACI) hydrogels are perfect candidates for carrying anionic drugs or molecules [50].
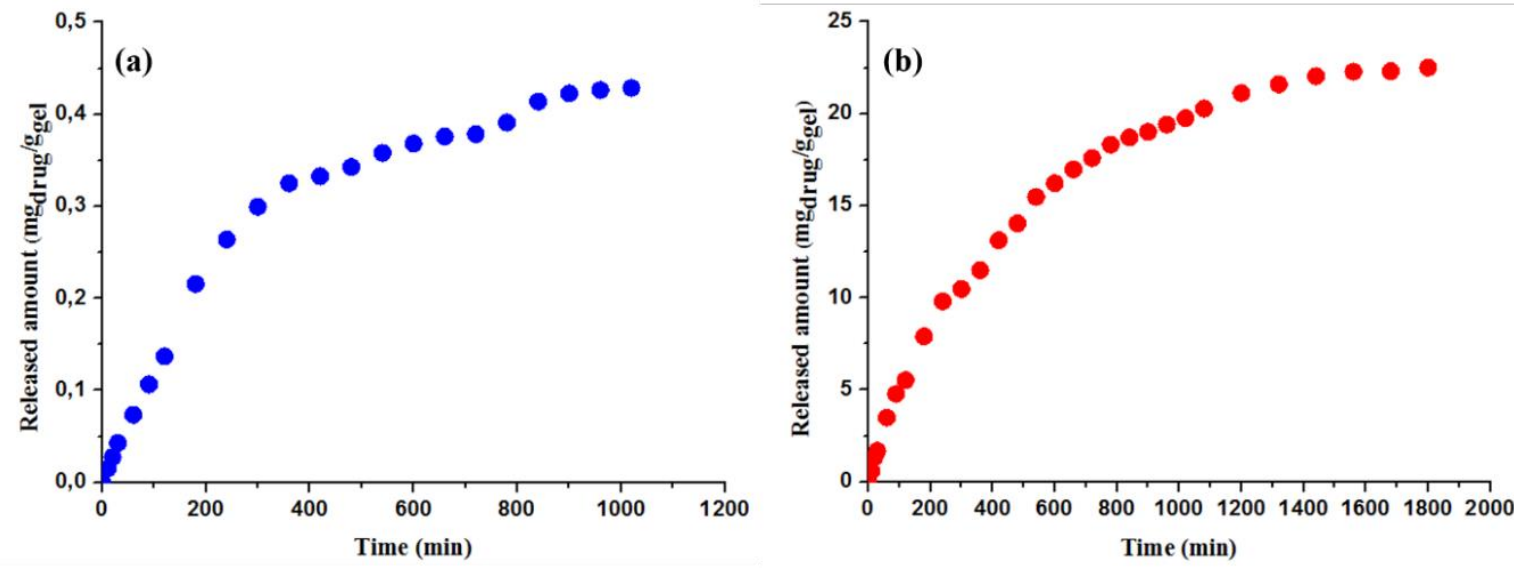

Figure 7. In vitro drug release behavior of (a) p(HEMA); (b) p(HEMA-co-APTMACl) for NaDc at PBS.

In vitro release studies of drug-loaded hydrogels were performed at a physiological temperature of $37^{\circ} \mathrm{C}$ in PBS media. The amount of drugs released from hydrogels $\left(\mathrm{mg}_{\text {drug }} / \mathrm{g}_{\text {gel }}\right)$ is given in Figure 7. When maximum amounts of drug released are examined, only 0.43 $\mathrm{mg}_{\text {drug }} / \mathrm{g}_{\text {gel }}(18 \%)$ was released at the end of 17 hours from $\mathrm{p}$ (HEMA) hydrogels (Figure 7(a)). For $\mathrm{p}(\mathrm{HEMA}-\mathrm{co}-\mathrm{APTMACI})$ hydrogels, $22.5 \mathrm{mg}_{\mathrm{drug}} / \mathrm{g}_{\mathrm{gel}}(62 \%)$ was released at the end of 30 hours (Figure 7(b)).

The $\mathrm{pK}_{\mathrm{a}}$ value of sodium diclofenac is 4 [51]. Solubility increases with the $\mathrm{pH}$ increase in weakly acidic material ( $\mathrm{pK}_{\mathrm{a}}$ : 2-14). A study by Rodríguez et al. proved this [52]. The increase in the ions found in the PBS medium ( $\mathrm{pH}=7.0)$ and the degree of ionization of the drug removes interactions between drug-hydrogel. This makes it possible for cationic hydrogels to have higher amounts of drug release compared to p(HEMA) hydrogel and allows for continuous release.

Table 2. Drug release parameters of hydrogels for sodium diclofenac.

\begin{tabular}{l|c|c|c} 
& $\mathbf{n}$ & $\mathbf{K}$ & $\mathbf{R}^{\mathbf{2}}$ \\
\hline $\mathbf{p}$ (HEMA) & 0,84 & $4,99 \times 10^{-3}$ & 0,991 \\
\hline p(HEMA-co-APTMACI) & 0,76 & $6,02 \times 10^{-3}$ & 0,987
\end{tabular}

The Korsmeyer-Peppas power law equation was used to understand the release mechanism of drugs from hydrogels. The diffusion constant (n), regression values $\left(\mathrm{R}^{2}\right)$ and drug release rate constant $(\mathrm{K})$ were calculated from the graph of $\ln t$ against $\ln \mathrm{Q}_{t} / \mathrm{Q}_{\infty}$. The values can be seen in Table 2. The regression values were 0.99 and 0.987 for $\mathrm{p}(\mathrm{HEMA})$ and p(HEMA-co-APTMACI) hydrogels, respectively, and showed good linearity. The $n$ values given in Table 2 were 0.84 for $\mathrm{p}$ (HEMA) hydrogel and 0.76 for $\mathrm{p}$ (HEMA-co-APTMACI) hydrogel. This situation shows the drug release mechanism for both hydrogels was nonFickian.

\subsection{Antibacterial activity.}

Currently, the interest in easily synthesized cationic hydrogels with suitable cost and antibacterial features is increasing. Cationic hydrogels contain cation groups like quaternized 
ammonium and phosphonium [53]. Cationic groups bind to negative-load phospholipids in the cell membrane of bacteria, disrupt membrane viscosity and cause the death of bacteria [54]. In antibacterial activity studies, p(HEMA) and p(HEMA-co-APTMACI) hydrogels both synthesized with the novel silica-based crosslinker were investigated for antibacterial activity against B. subtilis, E. coli and S. aureus. The disk diffusion method was used for antibacterial activity. Table 3 shows the inhibition effects of the hydrogels against bacteria. When the data is examined, the drug-loaded and non-loaded p(HEMA) hydrogels did not display any antibacterial features against the bacteria. When the inhibition zones created by p(HEMA-coAPTMACI) hydrogels containing cationic quaternized ammonium groups, loaded and not loaded with sodium diclofenac, are examined, large inhibition zones were observed for all bacteria. However, the largest zone was found for S. aureus (Figure 8).

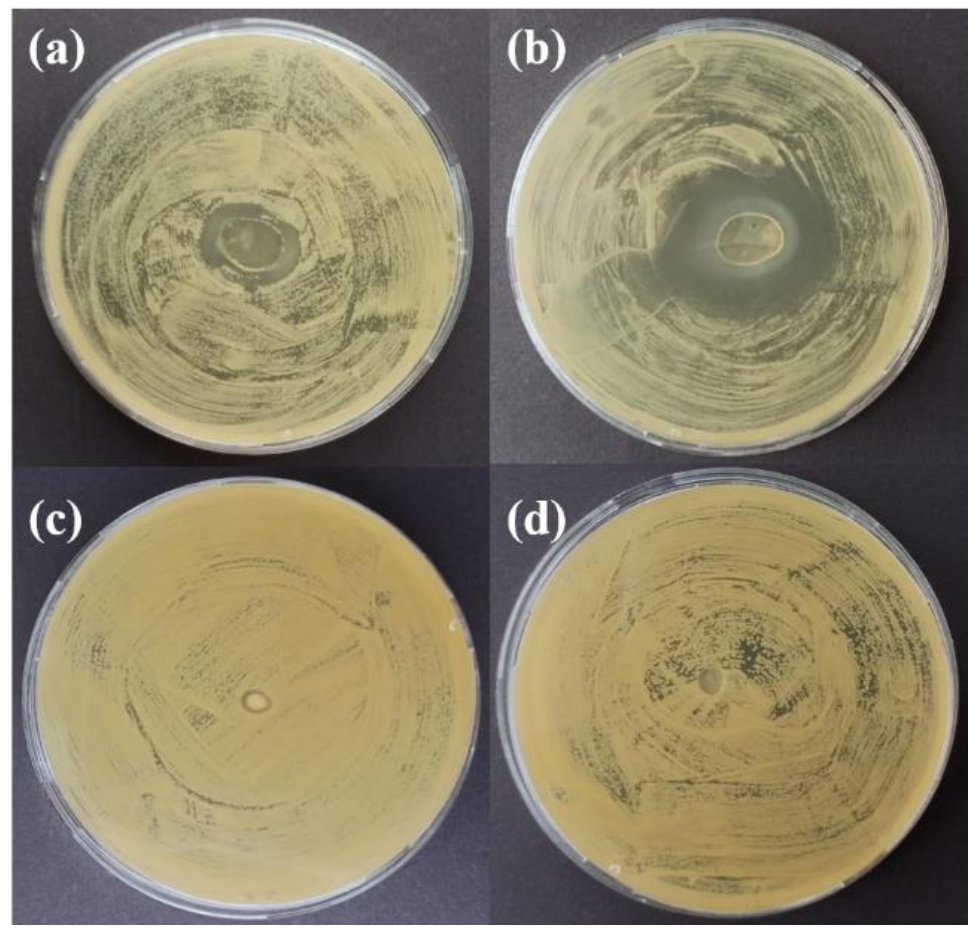

Figure 8. Digital camera images of antibacterial activity tests againts S.areus of drug-loaded and unloaded hydrogels (a) unloaded p(HEMA-co-APTMACl) hydrogels; (b) drug-loaded p(HEMA-co-APTMACl); (c) unloaded p(HEMA) hydrogels; (d) drug-loaded p(HEMA) hydrogels.

Based on the data in Table 3, the non-drug loaded p(HEMA-co-APTMACI) hydrogels appear to have antibacterial properties. The drug-loaded hydrogels appear to have an increase in antibacterial features. This indirectly confirms the release of drug molecules included within the hydrogels.

Table 3. The inhibition zone diameter $(\mathrm{mm})$ of hydrogels and drug-loaded hydrogels.

\begin{tabular}{l|c|c|c|c}
\hline & \multicolumn{2}{|c|}{ P(HEMA) } & \multicolumn{2}{c}{ P(HEMA-co-APTMACI) } \\
\hline & Hydrogels & $\begin{array}{c}\text { Drug-loaded } \\
\text { hydrogels }\end{array}$ & Hydrogels & $\begin{array}{c}\text { Drug-loaded } \\
\text { hydrogels }\end{array}$ \\
\hline S. aerus & - & - & 21 & 38 \\
\hline B. subtilis & - & - & 19 & 23 \\
\hline E. coli & - & - & 17 & 18 \\
\hline
\end{tabular}

\section{Conclusions}

In this study, a new type of silica-based crosslinker containing vinyl groups was successfully synthesized. Using the novel crosslinker, p(HEMA) and cationic p(HEMA-coAPTMACI) hydrogels were synthesized. Sodium diclofenac was loaded into hydrogels as a 
model drug for drug release studies. The amounts of the drug held by $\mathrm{p}$ (HEMA) and $\mathrm{p}$ (HEMAco-APTMACI) hydrogels were $2.3 \mathrm{mg}$ drug $/ \mathrm{g}_{\text {gel }}$ and $34 \mathrm{mg}$ drug $/ \mathrm{g}_{\text {gel }}$, respectively. As a result of drug release studies in PBS media, $\mathrm{p}(\mathrm{HEMA})$ hydrogels released $0.43 \mathrm{mg}$ drug $/ \mathrm{g}_{\text {gel }}(18 \%)$ at the end of 17 hours, while p(HEMA-co-APTMACI) hydrogels released $22.5 \mathrm{mg}$ drug $/ \mathrm{g}_{\text {gel }}(62 \%)$ at the end of 30 hours with a long-term release profile. Additionally, the antibacterial properties of hydrogels against E. coli, S. aureus, and B. subtilis bacteria were investigated. As a result of investigations, $\mathrm{p}$ (HEMA) hydrogels did not have antibacterial properties against investigated bacteria. However, p(HEMA-co-APTMACI) hydrogels displayed the highest effect against $S$. aureus bacteria but had antibacterial properties against all bacteria. With the study results, the synthesis of an inorganic/organic hybrid crosslinker was successfully carried out as an alternative to organic-derived crosslinkers used for hydrogel synthesis in the literature.

\section{Funding}

This research was funded by the Canakkale Onsekiz Mart University [FYL-2019-3106].

\section{Acknowledgments}

This study was produced from the master thesis of Betul Yilmaz.

\section{Conflicts of Interest}

The authors declare no conflict of interest.

\section{References}

1. Majeed, A.; Pervaiz, F.; Shoukat, H.; Shabbir, K.; Noreen, S.; Anwar, M. Fabrication and evaluation of pH sensitive chemically cross-linked interpenetrating network [Gelatin/Polyvinylpyrrolidone-co-poly(acrylic acid)] for targeted release of 5-fluorouracil. Polym. Bull. 2020, https://doi.org/10.1007/s00289-020-03489-6.

2. Abasian, P.; Shakibi, S.; Maniati, M.S.; Nouri Khorasani, S.; Khalili, S. Targeted delivery, drug release strategies, and toxicity study of polymeric drug nanocarriers. Polym. Adv. Technol. 2021, 32, 931-944, https://doi.org/10.1002/pat.5168.

3. Halamová, D.; Zeleňák, V. NSAID naproxen in mesoporous matrix MCM-41: drug uptake and release properties. J. Incl. Phenom. Macrocycl. Chem. 2012, 72, 15-23, https://doi.org/10.1007/s10847-011-9990-x.

4. Kasiński, A.; Zielińska-Pisklak, M.; Oledzka, E.; Nałęcz-Jawecki, G.; Drobniewska, A.; Sobczak, M. Hydrogels Based on Poly(Ether-Ester)s as Highly Controlled 5-Fluorouracil Delivery Systems-Synthesis and Characterization. Materials 2021, 14, https://doi.org/10.3390/ma14010098.

5. Aghebati-Maleki A.; Dolati S.; Ahmadi M.; Baghbanzhadeh A.; Asadi M.; Fotouhi A.; Yousefi M.; AghebatiMaleki L. Nanoparticles and cancer therapy: Perspectives for application of nanoparticles in the treatment of cancers. J. Cell. Physiol. 2020, 235, 1962-1972, https://doi.org/10.1002/jcp.29126.

6. Onaciu, A.; Munteanu, R.A.; Moldovan, A.I.; Moldovan, C.S.; Berindan-Neagoe, I. Hydrogels Based Drug Delivery Synthesis, Characterization and Administration. Pharmaceutics 2019, 11, 432 https://doi.org/10.3390/pharmaceutics11090432.

7. Ilgin, P.; Ozay, H.; Ozay, O. Synthesis and characterization of pH responsive alginate based-hydrogels as oral drug delivery carrier. Journal of Polymer Research 2020, 27, 251, https://doi.org/10.1007/s10965-02002231-0.

8. Peppas, N.A. Hydrogels and drug delivery. Current Opinion in Colloid \& Interface Science 1997, 2, 531537, https://doi.org/10.1016/S1359-0294(97)80103-3.

9. Maiz-Fernández, S.; Guaresti, O.; Pérez-Álvarez, L.; Ruiz-Rubio, L.; Gabilondo, N.; Vilas-Vilela, J.L.; Lanceros-Mendez, S. $\beta$-Glycerol phosphate/genipin chitosan hydrogels: A comparative study of their properties and diclofenac delivery. Carbohydr. Polym. 2020, 248, 116811, https://doi.org/10.1016/j.carbpol.2020.116811.

10. Ozay, H.; Sahin, O.; Koc, O.K.; Ozay, O. The preparation and applications of novel phosphazene cross-linked thermo and $\mathrm{pH}$ responsive hydrogels. Journal of Industrial and Engineering Chemistry 2016, 43, 28-35, http://dx.doi.org/10.1016/j.jiec.2016.07.043. 
11. Ghasemiyeh, P.; Mohammadi-Samani, S. Hydrogels as Drug Delivery Systems; Pros and Cons. Trends in Pharmaceutical Sciences 2019, 5, 7-24, https://doi.org/10.30476/TIPS.2019.81604.1002.

12. Gupta, P.; Vermani, K.; Garg, S. Hydrogels: from controlled release to pH-responsive drug delivery. Drug Discov. Today 2002, 7, 569-579, https://doi.org/10.1016/s1359-6446(02)02255-9.

13. Ramos, J.; Forcada, J.; Hidalgo-Alvarez, R. Cationic Polymer Nanoparticles and Nanogels: From Synthesis to Biotechnological Applications. Chem. Rev. 2014, 114, 367-428, https://doi.org/10.1021/cr3002643.

14. Nayeem, J.; Al-Bari, M.A.A.; Mahiuddin, M.; Rahman, M.A.; Mefford, O.T.; Ahmad, H.; Rahman, M.M. Silica coating of iron oxide magnetic nanoparticles by reverse microemulsion method and their functionalization with cationic polymer P(NIPAm-co-AMPTMA) for antibacterial vancomycin immobilization. Colloids Surf. Physicochem. Eng. Aspects 2021, 611, 125857, https://doi.org/10.1016/j.colsurfa.2020.125857.

15. Mendonça, P.V.; Konkolewicz, D.; Averick, S.E.; Serra, A.C.; Popov, A.V.; Guliashvili, T.; Matyjaszewski, K.; Coelho, J.F.J. Synthesis of cationic poly((3-acrylamidopropyl)trimethylammonium chloride) by SARA ATRP in ecofriendly solvent mixtures. Polymer Chemistry 2014, 5, 5829-5836, https://doi.org/10.1039/c4py00707g.

16. Grigoras, A.G.; Constantin, M.; Grigoras, V.C.; Dunca, S.I.; Ochiuz, L. Studies on physico-chemical and antibacterial properties of grafted pullulans solutions. React. Funct. Polym. 2013, 73, 1249-1254, https://doi.org/10.1016/j.reactfunctpolym.2013.06.009.

17. Tomić, S.L.; Mićić, M.M.; Dobić, S.N.; Filipović, J.M.; Suljovrujić, E.H. Smart poly(2-hydroxyethyl methacrylate/itaconic acid) hydrogels for biomedical application. Radiat. Phys. Chem. 2010, 79, 643-649, https://doi.org/10.1016/j.radphyschem.2009.11.015.

18. Zhang, Y.; Chu, D.; Zheng, M.; Kissel, T.; Agarwal, S. Biocompatible and degradable poly(2-hydroxyethyl methacrylate) based polymers for biomedical applications. Polymer Chemistry 2012, 3, 2752-2759, https://doi.org/10.1039/c2py20403g.

19. Kubinová, Š.; Horák, D.; Syková, E. Cholesterol-modified superporous poly(2-hydroxyethyl methacrylate) scaffolds for tissue engineering. Biomaterials 2009, 30, 4601-4609, https://doi.org/10.1016/j.biomaterials.2009.05.007.

20. Ijaz, H.; Tulain, U.R.; Minhas, M.U.; Mahmood, A.; Sarfraz, R.M.; Erum, A.; Danish, Z. Design and in vitro evaluation of $\mathrm{pH}$-sensitive cross-linked chitosan-grafted acrylic acid copolymer (CS-co-AA) for targeted drug delivery. International Journal of Polymeric Materials and Polymeric Biomaterials 2020, https://doi.org/10.1080/00914037.2020.1833011.

21. Okten Besli, N.S.; Orakdogen, N. Thermomechanical analysis and pH-triggered elastic response of chargebalanced sulfonated poly(tertiary amine-methacrylate)-based terpolymer cryogels. Polymer 2020, 208, 122941, https://doi.org/10.1016/j.polymer.2020.122941.

22. Huang, J.; Huang, Z.-M.; Bao, Y.-Z.; Weng, Z.-X. Synthesis and characterization of reinforced acrylic-based superabsorbents cross-linked with divinylbenzene. J. Appl. Polym. Sci. 2006, 100, 1594-1600, https://doi.org/10.1002/app.23604.

23. Xu, Y.; Zhai, X.; Su, P.; Liu, T.; Zhou, L.; Zhang, J.; Bao, B.; Wang, L. Highly stable semiconducting polymer nanoparticles for multi-responsive chemo/photothermal combined cancer therapy. Theranostics 2020, 10, 5966-5978, https://doi.org/10.7150/thno.43090.

24. Ferreira, L.; Vidal, M.M.; Gil, M.H. Evaluation of poly(2-hydroxyethyl methacrylate) gels as drug delivery systems at different $\mathrm{pH}$ values. Int. J. Pharm. 2000, 194, 169-180, https://doi.org/10.1016/S03785173(99)00375-0.

25. Liberman, A.; Mendez, N.; Trogler, W.C.; Kummel, A.C. Synthesis and surface functionalization of silica nanoparticles for nanomedicine. Surf. Sci. Rep. 2014, 69, 132-158, https://doi.org/10.1016/j.surfrep.2014.07.001.

26. Stöber, W.; Fink, A.; Bohn, E. Controlled growth of monodisperse silica spheres in the micron size range. $J$. Colloid Interface Sci. 1968, 26, 62-69, https://doi.org/10.1016/0021-9797(68)90272-5.

27. Bhar, R.; Kanwar, R.; Mehta, S.K. Surface engineering of nanoparticles anchored meso-macroporous silica heterostructure: An efficient adsorbent for DNA. Mater. Chem. Phys. 2020, 255, 123541, https://doi.org/10.1016/j.matchemphys.2020.123541.

28. Ganguly, S.; Das, N.C. Synthesis of a novel pH responsive phyllosilicate loaded polymeric hydrogel based on poly(acrylic acid-co-N-vinylpyrrolidone) and polyethylene glycol for drug delivery: modelling and kinetics study for the sustained release of an antibiotic drug. RSC Advances 2015, 5, 18312-18327, https://doi.org/10.1039/c4ra16119j.

29. Ekici, S.; Saraydin, D. Synthesis, Characterization and Evaluation of IPN Hydrogels for Antibiotic Release. Drug Deliv. 2004, 11, 381-388, https://doi.org/10.1080/10717540490884804. 
30. Pereira, A.G.B.; Nunes, C.S.; Rubira, A.F.; Muniz, E.C.; Fajardo, A.R. Effect of chitin nanowhiskers on mechanical and swelling properties of Gum Arabic hydrogels nanocomposites. Carbohydr. Polym. 2021, 266, 118116, https://doi.org/10.1016/j.carbpol.2021.118116.

31. Ilgin, P.; Ozay, H.; Ozay, O. A new dual stimuli responsive hydrogel: Modeling approaches for the prediction of drug loading and release profile. Eur. Polym. J. 2019, 113, 244-253, https://doi.org/10.1016/j.eurpolymj.2019.02.003.

32. Ozay, H.; Ozay, O. Synthesis and characterization of drug microspheres containing phosphazene for biomedical applications. Colloids Surf. Physicochem. Eng. Aspects 2014, 450, 99-105, https://doi.org/10.1016/j.colsurfa.2014.03.022.

33. 5 - Mathematical models of drug release. In Strategies to Modify the Drug Release from Pharmaceutical Systems, Bruschi, M.L., Ed. Woodhead Publishing: 2015, 63-68, https://doi.org/10.1016/B978-0-08-1000922.00005-9.

34. Newham, G.; Mathew, R.K.; Wurdak, H.; Evans, S.D.; Ong, Z.Y. Polyelectrolyte complex templated synthesis of monodisperse, sub-100 nm porous silica nanoparticles for cancer targeted and stimuli-responsive drug delivery. J. Colloid Interface Sci. 2021, 584, 669-683, https://doi.org/10.1016/j.jcis.2020.10.133.

35. Wang, J.; Yang, L.; Xie, J.; Wang, Y.; Wang, T.-J. Surface Amination of Silica Nanoparticles Using Tris(hydroxymethyl)aminomethane. Ind. Eng. Chem. Res. 2020, 59, 21383-21392, https://doi.org/10.1021/acs.iecr.0c04346.

36. Kimmins, S.D.; Wyman, P.; Cameron, N.R. Amine-functionalization of glycidyl methacrylate-containing emulsion-templated porous polymers and immobilization of proteinase K for biocatalysis. Polymer 2014, 55, 416-425, https://doi.org/10.1016/j.polymer.2013.09.019.

37. Han, X.; Wang, Y.; Zhang, N.; Meng, J.; Li, Y.; Liang, J. Facile synthesis of mesoporous silica derived from iron ore tailings for efficient adsorption of methylene blue. Colloids Surf. Physicochem. Eng. Aspects 2021, 617, 126391, https://doi.org/10.1016/j.colsurfa.2021.126391.

38. Guo, Q.; Huang, D.; Kou, X.; Cao, W.; Li, L.; Ge, L.; Li, J. Synthesis of disperse amorphous SiO2 nanoparticles via sol-gel process. Ceram. Int. 2017, 43, 192-196, https://doi.org/10.1016/j.ceramint.2016.09.133.

39. Dube, E.; Soy, R.; Shumba, M.; Nyokong, T. Photophysicochemical behaviour of phenoxy propanoic acid functionalised zinc phthalocyanines when grafted onto iron oxide and silica nanoparticles: Effects in photodynamic antimicrobial chemotherapy. J. Lumin. 2021, 234, 117939, https://doi.org/10.1016/j.jlumin.2021.117939.

40. Kunita, M.H.; Girotto, E.M.; Muniz, E.C.; Rubira, A.F. Polypropylene grafted with glycidyl methacrylate using supercritical CO2 medium. Brazilian Journal of Chemical Engineering 2006, 23, 267-271, https://doi.org/10.1590/S0104-66322006000200015.

41. Ozay, O.; Ilgin, P.; Ozay, H.; Gungor, Z.; Yilmaz, B.; Kıvanç, M.R. The preparation of various shapes and porosities of hydroxyethyl starch/p(HEMA-co-NVP) IPN hydrogels as programmable carrier for drug delivery. Journal of Macromolecular Science, Part A 2020, 57, 379-387, https://doi.org/10.1080/10601325.2019.1700803.

42. Sahiner, N.; Demirci, S.; Sahiner, M.; Yilmaz, S.; Al-Lohedan, H. The use of superporous p(3acrylamidopropyl)trimethyl ammonium chloride cryogels for removal of toxic arsenate anions. J. Environ. Manage. 2015, 152, 66-74, http://dx.doi.org/10.1016/j.jenvman.2015.01.023.

43. Senol, S.; Akyol, E. Synthesis and characterization of hydrogels based on poly(2-hydroxyethyl methacrylate) for drug delivery under UV irradiation. Journal of Materials Science 2018, 53, 14953-14963, https://doi.org/10.1007/s10853-018-2713-6.

44. Ilgin, P.; Ozay, H.; Ozay, O. The efficient removal of anionic and cationic dyes from aqueous media using hydroxyethyl starch-based hydrogels. Cellulose 2020, 27, 4787-4802, https://doi.org/10.1007/s10570-02003074-0.

45. Plumeré, N.; Ruff, A.; Speiser, B.; Feldmann, V.; Mayer, H.A. Stöber silica particles as basis for redox modifications: Particle shape, size, polydispersity, and porosity. J. Colloid Interface Sci. 2012, 368, 208-219, https://doi.org/10.1016/j.jcis.2011.10.070.

46. Li, R.; Guan, X.; Lin, X.; Guan, P.; Zhang, X.; Rao, Z.; Du, L.; Zhao, J.; Rong, J.; Zhao, J. Poly(2hydroxyethyl methacrylate)/ $\beta$-cyclodextrin-hyaluronan contact lens with tear protein adsorption resistance and sustained drug delivery for ophthalmic diseases. Acta Biomater. 2020, 110, 105-118, https://doi.org/10.1016/j.actbio.2020.04.002.

47. Erdem, M. Novel N-vinilimidazol based copolymeric hydrogels:Synthesis, characterization and swelling properties. J. Fac. Eng. Archit. Gaz. 2019, 34, 1469-1481, https://doi.org/10.17341/gazimmfd.460546.

48. Samchenko, Y.; Ulberg, Z.; Korotych, O. Multipurpose smart hydrogel systems. Adv. Colloid Interface Sci. 2011, 168, 247-262, https://doi.org/10.1016/j.cis.2011.06.005. 
49. Zhao, Y.; Yu, S.; Wu, X.; Dai, H.; Liu, W.; Tu, R.; Goto, T. Construction of macroporous magnesium phosphate-based bone cement with sustained drug release. Materials \& Design 2021, 200, 109466, https://doi.org/10.1016/j.matdes.2021.109466.

50. Wei, W.; Qi, X.; Li, J.; Zhong, Y.; Zuo, G.; Pan, X.; Su, T.; Zhang, J.; Dong, W. Synthesis and characterization of a novel cationic hydrogel base on salecan-g-PMAPTAC. Int. J. Biol. Macromol. 2017, 101, 474-480, https://doi.org/10.1016/j.ijbiomac.2017.03.106.

51. Boonsongrit, Y.; Mitrevej, A.; Mueller, B.W. Chitosan drug binding by ionic interaction. Eur. J. Pharm. Biopharm. 2006, 62, 267-274, https://doi.org/10.1016/j.ejpb.2005.09.002.

52. Rodríguez, R.a.; Alvarez-Lorenzo, C.; Concheiro, A. Cationic cellulose hydrogels: kinetics of the crosslinking process and characterization as $\mathrm{pH}$-/ion-sensitive drug delivery systems. J. Controlled Release 2003, 86, 253-265, https://doi.org/10.1016/S0168-3659(02)00410-8.

53. Du, H.; Wang, Y.; Yao, X.; Luo, Q.; Zhu, W.; Li, X.; Shen, Z. Injectable cationic hydrogels with high antibacterial activity and low toxicity. Polymer Chemistry 2016, 7, 5620-5624, https://doi.org/10.1039/C6PY01346E.

54. Shibata, Y.; Kurokawa, T.; Aizawa, T.; Gong, J.P. Bactericidal effect of cationic hydrogels prepared from hydrophilic polymers. J. Appl. Polym. Sci. 2020, 137, 49583, https://doi.org/10.1002/app.49583. 